\title{
The hypoxia-mimetic agent cobalt chloride induces cell cycle arrest and alters gene expression in $\mathbf{U} 266$ multiple myeloma cells
}

\author{
SEUNGHEE BAE ${ }^{1}$, HYE-JUNG JEONG ${ }^{1}$, HWA JUN CHA ${ }^{1}$, KARAM KIM $^{1}$, YEONG MIN CHOI ${ }^{1}$, \\ IN-SOOK AN ${ }^{2}$, HYEA JUNG KOH ${ }^{3}$, DAE JIN LIM ${ }^{4}$, SU-JAE LEE ${ }^{5}$ and SUNGKWAN AN ${ }^{1,2}$ \\ ${ }^{1}$ Molecular-Targeted Drug Research Center, Konkuk University; ${ }^{2}$ Korea Institute for Skin and Clinical Sciences, \\ Konkuk University, Gwangjin-gu, Seoul 143-701; ${ }^{3}$ Department of Beauty and Art, Suwon Women's College, \\ Kyounggi-do 441-748; ${ }^{4}$ Graduate School of Arts, Hansung University, Seoul 136-792; ${ }^{5}$ Department \\ of Chemistry, Hanyang University, Seongdong-gu, Seoul 133-791, Republic of Korea
}

Received May 24, 2012; Accepted July 27, 2012

DOI: $10.3892 /$ ijmm.2012.1115

\begin{abstract}
Hypoxia is a common feature of tumors that occurs across a wide variety of malignancies. Multiple myeloma is an incurable malignant disorder of plasma cells in the bone marrow. Although bone marrow hypoxia is crucial for normal hematopoiesis, the effect of hypoxia on multiple myeloma is poorly understood. In this study, we demonstrated that cobalt chloride $\left(\mathrm{CoCl}_{2}\right)$-mediated hypoxia decreased cell viability and altered gene expression in U266 human multiple myeloma cells. $\mathrm{CoCl}_{2}$ induced the loss of cell viability in a concentration-dependent manner. In addition, FACS analysis revealed that the loss of cell viability was related to apoptosis. Using microarray analysis, we identified mRNA expression profile changes in response to $\mathrm{CoCl}_{2}$ treatment in U266 cells. Four hundred and fifty-two mRNAs exhibited $>2$-fold changes in expression in $\mathrm{CoCl}_{2}-$ treated U266 cells compared to their expression in control cells. A follow-up bioinformatics study revealed that a great number of genes with altered expression were involved in apoptosis, cell cycle, transcription and development. In conclusion, these results provide novel evidence that $\mathrm{CoCl}_{2}$-mediated hypoxia affects the expression profiles of genes that are functionally related to apoptosis and angiogenesis in U266 multiple myeloma cells.
\end{abstract}

\section{Introduction}

Hypoxia, defined as areas with oxygen tension values of $10 \mathrm{mmHg}$ or lower, is a common feature of solid tumors that occurs across a wide variety of malignancies $(1,2)$. Once cells encounter hypoxia, a large number of genes that stimulate adaptation to oxygen deprivation are induced. These hypoxia-inducible genes are primarily controlled by the transcription factor hypoxia-inducible factor 1

Correspondence to: Dr Sungkwan An, Molecular-Targeted Drug Research Center, Konkuk University, 1 Hwayang-dong, Gwangjin-gu, Seoul 143-701, Republic of Korea

E-mail: ansfgrc@konkuk.ac.kr

Key words: hypoxia, multiple myeloma, cell cycle arrest, cobalt chloride, gene expression
(HIF-1), including those involved in cell cycle arrest, apoptosis, erythropoiesis, angiogenesis, glycolytic metabolism, and tumor invasiveness $(2,3)$. HIF-1 is a heterodimer consisting of a constitutively expressed HIF-1 $\beta$ subunit and a HIF- $1 \alpha$ subunit that is regulated in an oxygen-dependent manner (3). Under hypoxia, HIF-1 $\alpha$ can block its own degradation and thus induce its accumulation (3). Therefore, HIF-1 $\alpha$ is overexpressed in many cancer types and is associated with poor prognosis in cancers of the breast, brain, cervix, ovary, and uterus (3).

HIF-1 $\alpha$ activation in response to hypoxia stimulates the transcription of several of its target genes. Vascular endothelial growth factor (VEGF), which is known to promote angiogenesis, is strongly induced by HIF-1 $\alpha$ (4). In addition, matrix metalloproteinase (MMP)-1 and MMP-2 are induced to promote intravasation $(5,6)$. Additionally, the epithelial-mesenchymal transition-inducing genes E-cadherin, SNAIL, TWIST, TCF3, and ZEB1 are up-regulated in a HIF-1 $\alpha$-dependent manner (7-9). Interestingly, HIF-1 $\alpha$ also induces cell cycle arrest by up-regulating p53, p21, and E1B $19 \mathrm{~K} / \mathrm{Bcl}-2$ binding protein Nip3 expression (10-12). These findings suggest that there are different adaptive responses to oxygen deprivation.

Cobalt chloride $\left(\mathrm{CoCl}_{2}\right)$, a commonly used hypoxia-mimetic agent, artificially induces hypoxia and can block the degradation and thus induce the accumulation of HIF-1 $\alpha$ protein $(13,14)$. Many reports have indicated that both $\mathrm{CoCl}_{2}$ and hypoxia regulate a similar group of genes on a global gene expression level (15-17). In addition, the reports demonstrated that hypoxia and $\mathrm{CoCl}_{2}$ induced different effects in many different types of cells. For example, $\mathrm{CoCl}_{2}$ induced apoptosis in rat $\mathrm{C} 6$ glioma cells, human alveolar macrophages, neuronal PC12 cells, and HeLa human cervical cancer cells, although it inhibited apoptotic death in HepG2 hepatoma cells (18-22). Moreover, $\mathrm{CoCl}_{2}$ induced prostate tumor cell adhesion, metastasis, and angiogenesis (23-25) and stimulated oral squamous carcinoma cell growth (26).

Multiple myeloma (MM) is a B-cell malignancy selectively localized in the bone marrow (BM) (27). Unlike other organs, the normal BM microenvironment is hypoxic. This physiological hypoxia is crucial for normal marrow hematopoiesis (28). In several studies, oxygen levels in BM in mice with MM were depressed $(29,30)$. This hypoxia is an important microenvironmental stimulus for activities critical for MM disease progression 
such as MM cell growth, drug resistance, and angiogenesis $(29,30)$. However, how hypoxia and MM affect each other is poorly understood. Therefore, an investigation of the effects of hypoxia on myeloma cells is necessary.

\section{Materials and methods}

Cell culture. The human multiple myeloma cell line U266 was purchased from the Korean Cell Line Bank (Seoul, Korea) and cultured in RPMI-1640 medium containing $10 \%$ fetal bovine serum and antibiotics at $37^{\circ} \mathrm{C}$ in a humidified chamber containing $5 \% \mathrm{CO}_{2}$. Cells were seeded into 60-mm culture dishes ( $4 \times 10^{5}$ cells per dish) 1 day before $\mathrm{CoCl}_{2}$ (Sigma, St. Louis, MO, USA) treatment.

Hypoxia induction. $\mathrm{CoCl}_{2}$ was dissolved in dimethylsulfoxide (DMSO; Sigma) and added to U266 cultures at the indicated final concentrations. DMSO was added to culture medium alone as a vehicle control. Cells were treated for $24 \mathrm{~h}$.

RNA preparation and cDNA synthesis. Total RNA was extracted from cells by using TRIzol reagent (Invitrogen, Carlsbad, CA, USA) according to the manufacturer's instructions after the 24-h $\mathrm{CoCl}_{2}$ treatment. For the microarray studies, both the quality and concentration of the RNA samples were determined using an Agilent 2100 Bioanalyzer (Agilent Technologies, Santa Clara, CA, USA) and an Ultrospec 3300 Pro UV/Visible Spectrophotometer (Amersham Biosciences, UK). The recommended RNA quality parameters for microarray analysis are as follows: a UV spectroscopy A260/A280 ratio of 1.8-2.0 and an A260/A230 ratio $>1.8$, an 18S/28S rRNA ratio of 1.8-2.1, and an RNA integrity number $>8.0$. To synthesize cDNA, $1 \mu \mathrm{g}$ of RNA was incubated with oligo-dT primers at $94^{\circ} \mathrm{C}$ for $10 \mathrm{~min}$ and reverse-transcribed with reverse transcriptase (Enzynomics, Seoul, Korea) at $37^{\circ} \mathrm{C}$ for $1 \mathrm{~h}$.

DNA microarray analysis. DNA microarray analysis was performed using the HumanHT-12 v4.0 Expression Beadchip kit (Illumina, San Diego, CA, USA) according to the instruction manual. Derived data were analyzed using Genespring GX 11 (Agilent Technologies). The raw data were filtered using FLAG and t-tests. Significant genes were determined using the fluorescence ratio between the control and $\mathrm{CoCl}_{2}$-treated samples, and genes displaying a >2-fold increase or decrease were selected for analysis.

Immunoblotting and polymerase chain reaction (PCR). Immunoblot analysis was performed as described previously (31). A primary antibody specific for HIF-1 $\alpha$ was purchased from Cell Signaling Technology (Danvers, MA, USA). Anti- $\beta$-actin antibody was purchased from Sigma. The expression level of VEGF mRNA was determined by quantitative real-time (RT)-PCR using specific primers (forward, 5'-AAGGAGGAGGGCAGAATCAT-3'; reverse, 5'-GCTGTAGGAAGCTCATCTCT-3'). RT-PCR analysis was performed using Line-Gene K software (Bioer Technology Co. Ltd., Hangzhou, China).

Cell viability assay and FACS analysis. Cell proliferation was determined using the WST-1 assay (EZ-Cytox Cell Viability
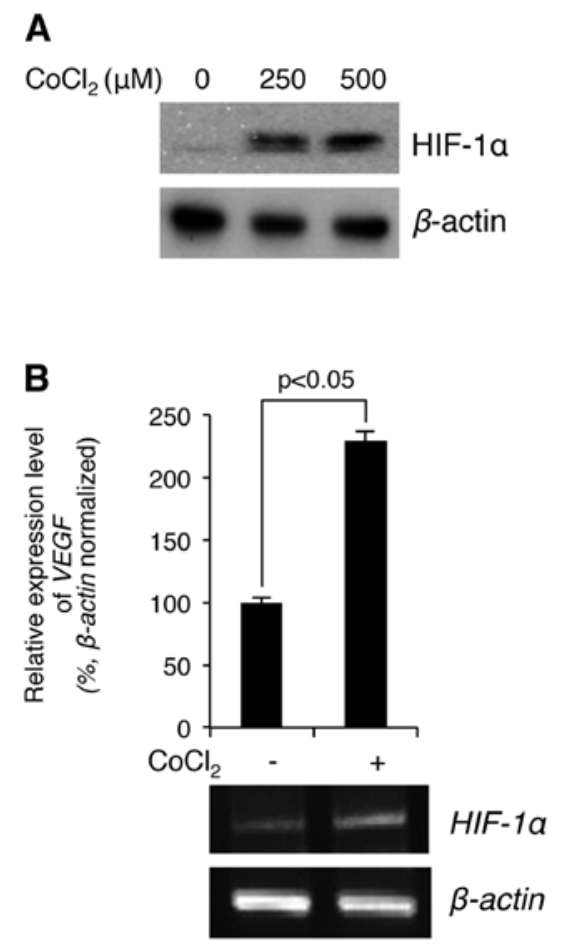

Figure 1. $\mathrm{CoCl}_{2}$ induces HIF-1 $\alpha$ accumulation and VEGF expression in MM U266 cells. (A) $\mathrm{CoCl}_{2}$ up-regulated the protein expression of HIF-1 $\alpha$ in U266 cells. U266 cells were treated with $\mathrm{CoCl}_{2}$ for $4 \mathrm{~h}$, and then the lysate was subjected to western blotting using the indicated antibodies. (B) $\mathrm{CoCl}_{2}$ increased VEGF mRNA expression in U266 cells. The cells were treated with DMSO (control) or $250 \mu \mathrm{M} \mathrm{CoCl}_{2}$ for $4 \mathrm{~h}$. VEGF mRNA expression was determined by RT-PCR. The results are representative of three independent experiments (means $\pm \mathrm{SD}$ ). Statistical differences in the findings between control cells and $\mathrm{CoCl}_{2}$-treated cells were indicated by $\mathrm{p}<0.05$.

Assay kit, ITSBIO, Korea) according to the manufacturer's instructions. In brief, $4 \times 10^{5}$ cells were seeded in $60-\mathrm{mm}$ dishes. The cells were cultured for $24 \mathrm{~h}$ and treated with the indicated concentrations of $\mathrm{CoCl}_{2}$ for $24 \mathrm{~h}$. At each time-point, the kit solution was added to cultured cells, which were incubated at $37^{\circ} \mathrm{C}$ for $30 \mathrm{~min}$. Cell viability was measured using an iMark microplate reader (Bio-Rad, Hercules, CA, USA) at $450 \mathrm{~nm}$ by using a $620-\mathrm{nm}$ reference filter. Cell cycle distribution was determined using FACS analysis. U266 cells were collected and fixed by resuspending them in $70 \%$ ethanol for $1 \mathrm{~h}$, centrifuged, and washed in cold PBS. The cell pellets were resuspended in PBS containing $50 \mu \mathrm{g} / \mathrm{ml}$ propidium iodide (Sigma) and $100 \mu \mathrm{g} /$ $\mathrm{ml}$ RNase, incubated at room temperature for $30 \mathrm{~min}$, and then analyzed using a FACScalibur (BD Biosciences, San Jose, CA, USA).

Statistical analysis. Statistical analysis was performed using the $\chi^{2}$ test or Fisher's exact test and Spearman rank correlation coefficient analysis. $\mathrm{p}<0.05$ was considered significant.

\section{Results and Discussion}

We first examined whether $\mathrm{CoCl}_{2}$ stimulation induces hypoxia in MM U266 cells. The cells were treated with the indicated concentrations of $\mathrm{CoCl}_{2}$ for $4 \mathrm{~h}$, and then the level of hypoxia was determined by immunoblotting against the hypoxia marker HIF-1 $\alpha$. As shown in Fig. 1A, the cellular protein levels of 


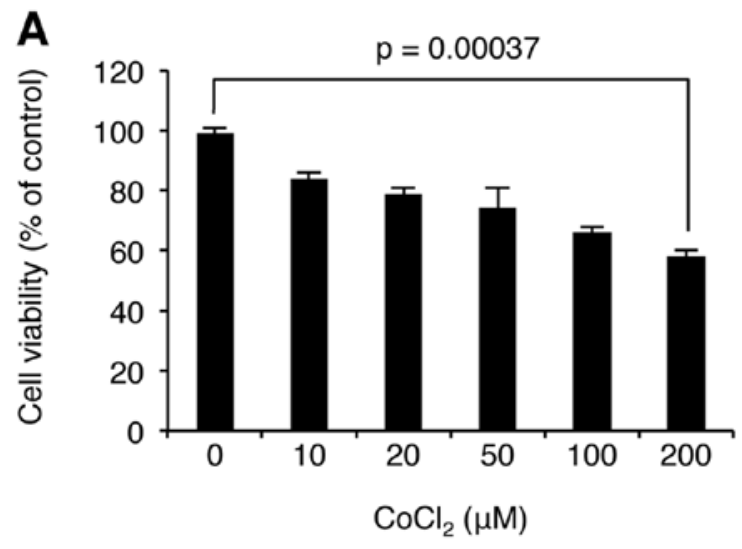

B
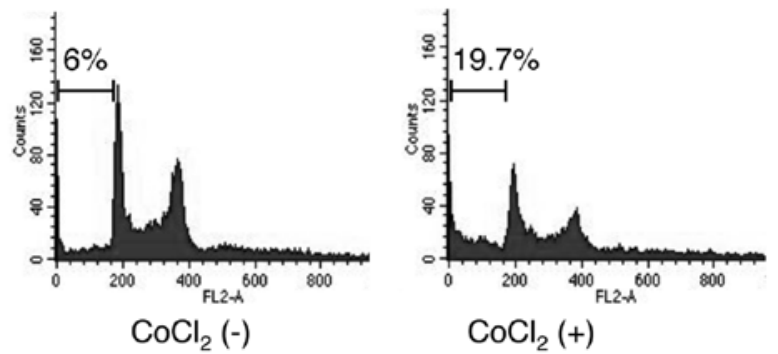

Figure 2. $\mathrm{CoCl}_{2}$-induced loss of cell viability and apoptosis in U266 cells. (A) Higher concentrations of $\mathrm{CoCl}_{2}$ reduced the viability of U266 cells. The cells were treated with the indicated concentrations $(\mu \mathrm{M})$ of $\mathrm{CoCl}_{2}$ for $24 \mathrm{~h}$. Cell viability was measured by the WST-1 assay. The columns and bars represent the mean $\pm \mathrm{SD}$, respectively, of experiments performed in triplicate. Statistical differences in the findings between control cells and $\mathrm{CoCl}_{2}$-treated cells were indicated by $\mathrm{p}<0.05$. (B) $\mathrm{CoCl}_{2}$ induced apoptotic cell death in U266 cells. U266 cells were treated with DMSO (control) or $100 \mu \mathrm{M} \mathrm{CoCl}_{2}$ for $24 \mathrm{~h}$. Cells were collected, fixed, stained with propidium iodide, and subjected to FACS.
$\mathrm{HIF}-1 \alpha$ were greatly increased in a $\mathrm{CoCl}_{2}$ concentrationdependent manner. Further, to test whether the accumulated HIF-1 $\alpha$ is functionally active in the cells, the expression level of a well-known HIF-1 $\alpha$ target gene, $V E G F$, was verified by RT-PCR using its specific primers (see Materials and methods). As shown in Fig. 1B, the mRNA expression levels of VEGF were up-regulated by $\mathrm{CoCl}_{2}$ stimulation in $\mathrm{U} 266$ cells. Therefore, the hypoxia-mimetic agent $\mathrm{CoCl}_{2}$ induced hypoxia in $\mathrm{U} 266$ cells.

As hypoxia has dual roles in cell proliferation and cell death, we examined the effect of hypoxia on MM cell proliferation. U266 cells were stimulated with $\mathrm{CoCl}_{2}$ at the indicated concentrations for $24 \mathrm{~h}$, and then WST-1-based cell viability assay was used to determine the level of cell proliferation. As shown in Fig. 2, $\mathrm{CoCl}_{2}$ decreased cell viability in a concentrationdependent manner. We next examined whether the loss of cell viability is related to cell cycle arrest or apoptosis. Interestingly, FACS analysis revealed that $\mathrm{CoCl}_{2}$ stimulation induces apoptosis, but not cell cycle arrest. These results indicate that the hypoxia induced cell death in U266 cells.

Although hypoxia alters cell type-specific gene expression patterns (32), its effects have been not fully studied in MM cells. Therefore, we analyzed mRNA profiles using Illumina Human HT-12 v4.0 Beadchip kits in hypoxia-stimulated and control U266 cells. A total of 47,000 human mRNAs were selected to analyze gene expression profiles. Those human genes were continually filtered with FLAG to obtain more defined data using Agilent GeneSpring GX 11 software. We selected total 452 human mRNAs as a result of FLAG filtration, and the genes displaying $>2$-fold differences in expression between the control and $\mathrm{CoCl}_{2}$-treated cells are shown in Fig. 3A. In addition, the mRNA microarray was visualized on a scatter
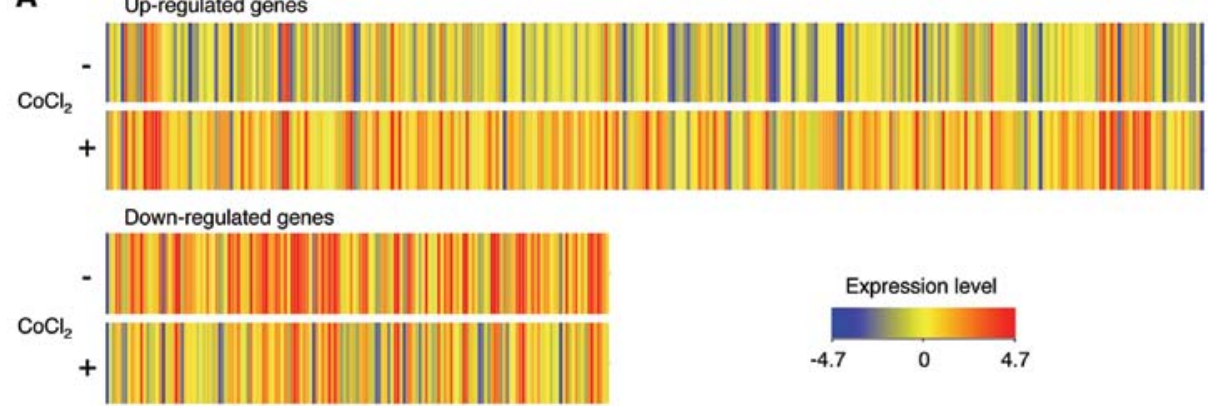

B

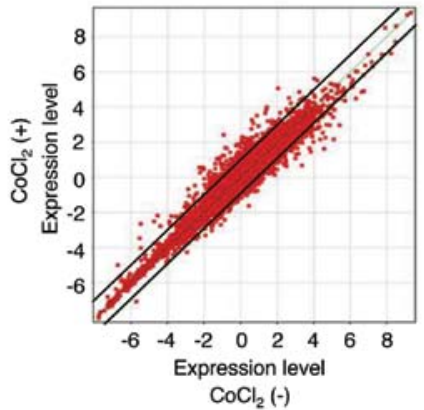

C

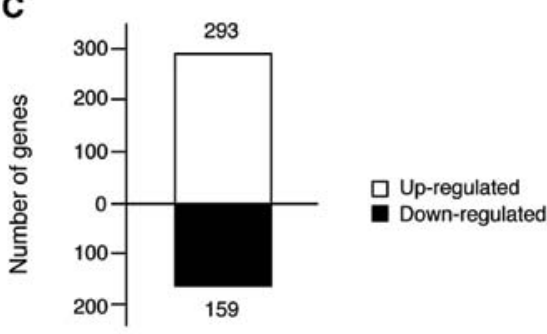

Figure 3. Gene expression profiling changes in response to $\mathrm{CoCl}_{2}$-mediated hypoxia in $\mathrm{U} 266$ cells. (A) $\mathrm{CoCl} \mathrm{Cl}_{2}$ treatment altered gene expression profiles. After treatment of $\mathrm{U} 266$ cells with $100 \mu \mathrm{M} \mathrm{CoCl}_{2}$ for $24 \mathrm{~h}$, RNA samples were purified and subjected to mRNA microarray analysis. Genes displaying $>2$-fold changes in their expression were selected, and the degree of change in expression is represented by color. (B) Scatter plot of that 452 genes that were regulated by $\mathrm{CoCl}_{2}$ in $\mathrm{U} 266$ cells. Scatter plot of differentially expressed genes between DMSO- and $\mathrm{CoCl}_{2}$-treated cells. The two lines parallel to the diagonal in the graph represent the 2 -fold ratio of expression level. (C) The numbers of mRNAs up- and downregulated $>2$-fold by $\mathrm{CoCl}_{2}$ treatment in $\mathrm{U} 266$ cells. 
Table I. Top 50 genes altered by treatment with cobalt chloride. ${ }^{\mathrm{a}}$

\begin{tabular}{lllllllll}
\hline & Up-regulated genes & & & \multicolumn{2}{l}{ Down-regulated genes } \\
Gene name & F.C & Gene name & F.C & & Gene name & F.C & Gene name & F.C \\
\hline OKL38 & 10.5 & MT1A & 4.19 & & HEMGN & 7.56 & XK & 2.69 \\
RN7SK & 8.34 & C17ORF91 & 4.12 & & RHOXF2B & 5.29 & EIF2AK2 & 2.66 \\
EMP1 & 7.15 & RAB7B & 4.07 & & TSPAN32 & 5.12 & ACSM3 & 2.61 \\
TXNRD1 & 7.14 & MT1X & 4.01 & & RHOXF2 & 5.00 & VEGFB & 2.60 \\
CDK5RAP2 & 6.40 & CTH & 3.94 & & TESC & 4.52 & SLC10A4 & 2.60 \\
SRXN1 & 6.35 & SLC3A2 & 3.83 & & ARHGAP22 & 4.11 & BOLA3 & 2.56 \\
C12ORF48 & 6.33 & UGDH & 3.81 & & KISS1R & 3.76 & C5ORF13 & 2.53 \\
AGPAT9 & 6.03 & ARRDC4 & 3.77 & & GYPA & 3.75 & GAD1 & 2.48 \\
NDRG1 & 5.90 & SLCO2B1 & 3.74 & & GYPE & 3.67 & HADH & 2.48 \\
UPP1 & 5.79 & NOTCH1 & 3.52 & & RHAG & 3.32 & MYB & 2.47 \\
CTSL1 & 5.74 & MT1E & 3.48 & & GAD1 & 3.24 & SPR & 2.47 \\
SLC7A11 & 5.44 & CD53 & 3.38 & & STAT5A & 3.22 & TFDP2 & 2.46 \\
CD44 & 5.32 & SERPINE2 & 3.40 & & CA1 & 3.21 & METTL7A & 2.45 \\
FLNB & 5.23 & ITPR1 & 3.37 & & SCARB1 & 3.13 & ATP5G1 & 2.45 \\
INHBE & 5.07 & RN5S9 & 3.32 & & ELOVL6 & 3.05 & C4ORF18 & 2.43 \\
GCLM & 4.78 & DCUN1D3 & 3.28 & & NME4 & 3.05 & NMRAL1 & 2.42 \\
FAM129B & 4.78 & ISG20 & 3.25 & & NFE2 & 3.02 & BEX4 & 2.42 \\
BCL6 & 4.74 & CEBPB & 3.24 & & CCDC34 & 2.99 & CYP3A5 & 2.42 \\
EID3 & 4.70 & PRSS2 & 3.22 & & ATF5 & 2.96 & CFD & 2.42 \\
MT2A & 4.66 & KLF6 & 3.18 & & KCNH2 & 2.94 & SLC1A3 & 2.42 \\
DUSP5 & 4.62 & PHLDA1 & 3.16 & & STS-1 & 2.83 & SOX21 & 2.41 \\
XIRP1 & 4.59 & PAEP & 3.13 & & ACPP & 2.82 & RELN & 2.41 \\
OSGIN1 & 4.31 & KIAA1666 & 3.12 & & ZNF121 & 2.73 & SPIN4 & 2.40 \\
SLC3A2 & 4.28 & IER5 & 3.10 & & GATA1 & 2.73 & EVL & 2.39 \\
ADM & 4.24 & LGMN & 3.09 & & LIPH & 2.71 & PIK3R2 & 2.39 \\
\hline
\end{tabular}

${ }^{a}$ The list was selected to show only the top 50 genes displaying $>2$-fold expression changes after FLAG sorting. Predicted genes were not selected in this list.

plot (Fig. 3B). The data of the scatter blot demonstrated that many genes displayed $>2$-fold differences in expression levels between control and $\mathrm{CoCl}_{2}$-treated cells, as indicated by their distance from the diagonal line. The numbers of up- and downregulated mRNAs exhibiting $>2$-fold changes were derived from the expression patterns in each group. We found that 293 up-regulated and 159 down-regulated mRNA displayed meaningful changes in their transcription profiles in response to $\mathrm{CoCl}_{2}$ treatment (Fig. 3C). The 50 genes for which their expression was most strongly altered by $\mathrm{CoCl}_{2}$ are listed in Table I. To further analyze the changes in gene expression patterns, we sorted the genes displaying $>2$-fold changes in expression after $\mathrm{CoCl}_{2}$ treatment into several groups according to common features such as homology or biochemical activity by using the Gene Set Enrichment Analysis bioinformatics tool (www. broadiinstitute.org/gsea), and we revealed that the sorted gene sets were categorized into transcription factors, cell differentiation markers, cytokines and growth factors, protein kinases, tumor suppressors, and oncogenes (Table II). Moreover, we further identified the cellular process pattern of $\mathrm{CoCl}_{2}$-induced gene expression changes by using the gene ontology database. Although the analysis of cellular process pattern was firstly performed using genes with $>2$-fold changes in expression, the pattern results were not sufficient for elucidation because the p-values of each category were $>0.05$; therefore, the analysis was re-performed on genes with $>1.5$-fold changes in expression, and the patterns with p-values $<0.05$ were selected. As shown in Fig. 4A, we first identified the genomic region responsible for gene expression changes induced in response to $\mathrm{CoCl}_{2}$ treatment in $\mathrm{U} 266$ cells by sorting the genes according to their chromosomal positions and revealed that the regions within ch11q13 and ch11q21 (up-regulated genes) and ch19p13 and ch6p21 (down-regulated genes) were the top two chromosome regions. Next, we grouped the genes according to cellular process and found that the up-regulated genes were related to apoptosis, development, cell cycle regulation, immunity, transcription, and B cell activation; however, the downregulated genes were related to cell cycle regulation, transcription, and 
Table II. Genes sharing a common feature such as homology or biochemical activity. ${ }^{\text {a }}$

\begin{tabular}{|c|c|c|c|c|c|c|c|c|}
\hline & $\begin{array}{l}\text { Cytokines } \\
\text { and growth } \\
\text { factors }\end{array}$ & $\begin{array}{l}\text { Transcription } \\
\text { factors }\end{array}$ & $\begin{array}{c}\text { Homeo- } \\
\text { domain } \\
\text { proteins }\end{array}$ & $\begin{array}{c}\text { Cell } \\
\text { differentiation } \\
\text { markers }\end{array}$ & $\begin{array}{l}\text { Protein } \\
\text { kinases }\end{array}$ & $\begin{array}{c}\text { Translocated } \\
\text { cancer } \\
\text { genes }\end{array}$ & Oncogenes & $\begin{array}{c}\text { Tumor } \\
\text { suppressors }\end{array}$ \\
\hline $\begin{array}{l}\text { Tumor } \\
\text { suppressor }\end{array}$ & 0 & $\begin{array}{c}1 \\
(1 / 0)\end{array}$ & 0 & 0 & 0 & 0 & 0 & $\begin{array}{c}2 \\
(1 / 1)\end{array}$ \\
\hline Oncogenes & 0 & $\begin{array}{c}5 \\
(2 / 3)\end{array}$ & 0 & 0 & $\begin{array}{c}1 \\
(1 / 0)\end{array}$ & $\begin{array}{c}8 \\
(6 / 2)\end{array}$ & $\begin{array}{c}9 \\
(6 / 3)\end{array}$ & \\
\hline $\begin{array}{l}\text { Translocated } \\
\text { cancer genes }\end{array}$ & 0 & $\begin{array}{c}4 \\
(2 / 2)\end{array}$ & 0 & 0 & $\begin{array}{c}1 \\
(1 / 0)\end{array}$ & $\begin{array}{c}8 \\
(6 / 2)\end{array}$ & & \\
\hline Protein kinases & 0 & 0 & 0 & 0 & $\begin{array}{c}10 \\
(6 / 4)\end{array}$ & & & \\
\hline $\begin{array}{l}\text { Cell differentiation } \\
\text { markers }\end{array}$ & $\begin{array}{c}1 \\
(1 / 0)\end{array}$ & 0 & 0 & $\begin{array}{c}18 \\
(14 / 4)\end{array}$ & & & & \\
\hline $\begin{array}{l}\text { Homeodomain } \\
\text { proteins }\end{array}$ & 0 & 0 & $\begin{array}{c}2 \\
(0 / 2)\end{array}$ & & & & & \\
\hline $\begin{array}{l}\text { Transcription } \\
\text { factors }\end{array}$ & 0 & $\begin{array}{c}33 \\
(18 / 15)\end{array}$ & & & & & & \\
\hline $\begin{array}{l}\text { Cytokines and } \\
\text { growth factors }\end{array}$ & $\begin{array}{c}15 \\
(12 / 3)\end{array}$ & & & & & & & \\
\hline
\end{tabular}

${ }^{\mathrm{a}}$ Genes displaying $>$ 2-fold expression changes after FLAG sorting were sorted according to shared biological features. Predicted genes were not selected in this list. The numbers of up- and down-regulated genes are presented in parentheses (up/down).
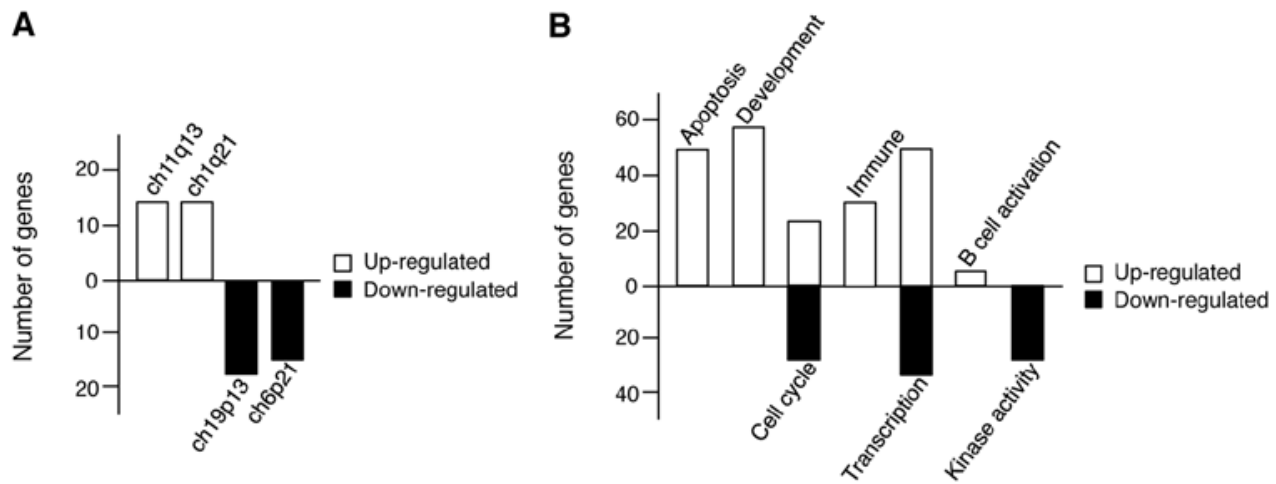

Figure 4. Categories of genes affected by $\mathrm{CoCl}_{2}$ treatment. (A) The top two chromosomal regions responsible for the gene expression changes induced by $\mathrm{CoCl}_{2}$. The common regions in each chromosome in which genes expression was changed by $>1.5$-fold were sorted by the Gene Set Enrichment Analysis tool. (B) Biological processes of genes up- or downregulated by $\mathrm{CoCl}_{2}$ treatment in U266 cells. The common biological processes were analyzed using the Gene Set Enrichment Analysis tool.

kinase activity (Fig. 4B). In particular, there are more changes among genes associated with both apoptosis and development, implying that in MM, hypoxia exerts both antitumor effects, and positively regulates cell proliferation pathways, although cell viability was decreased in hypoxic conditions.

Although both control BM and myeloma-infiltrated BM are hypoxic, the hypoxic level in myelomatous BM was revealed to be much lower than that in native $\mathrm{BM}$, as confirmed by the lower expression level of HIF-1 $\alpha$ in myelomatous BM than in native BM (29). These results imply that BM hypoxia is decreased during the progression of myeloma. Interestingly, using the 5T2 multiple myeloma mouse model, native BM hypoxia induced both apoptotic cell death of CD45- MM cells and exerted tumor-initiating effects on CD45+ MM cells (29). Additionally, 
blocking angiogenesis in this model restores the native BM hypoxia and results in apoptosis and suppressed proliferation of the MM cells (29). Furthermore, VEGF, a key angiogenic factor and a HIF-1 $\alpha$-responsive gene, is induced in CD45-5T2MM cells but not in $\mathrm{CD}^{4} 5^{+}$TT2MM cells (29). These data indicate that although BM hypoxia decreased the proliferation of CD45 MM cells, angiogenesis was induced, thus permitting outgrowth of the CD45- MM cells. Similarly, the microarray data in this study revealed that up-regulated genes were associated with both apoptosis and development. The MM U266 cells used in this study were CD45-. Therefore, although hypoxia induces U266 cell death by up-regulating apoptosis-related gene expression, resistance mechanisms for hypoxia were also induced via the up-regulation of development-related genes including VEGF and CD44.

In the microarray data, oxidative stress induced growth inhibitor 1 (OKL38) was the gene most strongly up-regulated by $\mathrm{CoCl}_{2}$ treatment (fold change $=10.52$ ). OKL38 is a tumor suppressor gene, and its overexpression inhibits tumor cell growth and induces apoptosis $(33,34)$. Although the effect in hypoxia on OKL38 has not been researched, hypoxia-mediated cell death could be dependent on OKL38 expression. In addition, $\mathrm{CD} 44$ was highly up-regulated by $\mathrm{CoCl}_{2}$ in U266 cells (fold change $=5.32$ ). CD44 is an antigen glycoprotein that plays an important role in aspects of cancer progression including growth promotion, angiogenesis, and metastasis (35); however, its cellular function in hypoxia has not yet been elucidated. Therefore, the hypoxia-induced up-regulation of CD44 in U266 cells indicates that CD44 is a novel key protein controlling hypoxia resistance mechanisms including angiogenesis in MM cells.

In conclusion, we first examined the diversity of gene expression responses to hypoxia in MM cells and found significant differences in gene expression. Additionally, although hypoxia induced apoptosis, the gene expression patterns indicated the activation of both antitumor and hypoxia resistance processes. Therefore, our results may provide a useful approach to understanding cellular responses to hypoxia.

\section{Acknowledgements}

We are grateful to all members of our research group for their support and advice regarding this study. This study resulted from the Konkuk University Research Support Program.

\section{References}

1. Lu X and Kang Y: Hypoxia and hypoxia-inducible factors: master regulators of metastasis. Clin Cancer Res 16: 5928-5935, 2010.

2. Harris AL: Hypoxia, a key regulatory factor in tumour growth. Nat Rev Cancer 2: 38-47, 2002.

3. Semenza GL: Targeting HIF-1 for cancer therapy. Nat Rev Cancer 3: 721-732, 2003.

4. Sullivan R and Graham CH: Hypoxia-driven selection of the metastatic phenotype. Cancer Metastasis Rev 26: 319-331, 2007.

5. Gupta GP, Nguyen DX, Chiang AC, et al: Mediators of vascular remodelling co-opted for sequential steps in lung metastasis. Nature 446: 765-770, 2007.

6. Shyu KG, Hsu FL, Wang MJ, Wang BW and Lin S: Hypoxiainducible factor lalpha regulates lung adenocarcinoma cell invasion. Exp Cell Res 313: 1181-1191, 2007.

7. Imai T, Horiuchi A, Wang C, et al: Hypoxia attenuates the expression of E-cadherin via up-regulation of SNAIL in ovarian carcinoma cells. Am J Pathol 163: 1437-1447, 2003.
8. Yang MH, Wu MZ, Chiou SH, et al: Direct regulation of TWIST by HIF-1alpha promotes metastasis. Nat Cell Biol 10: 295-305, 2008.

9. Krishnamachary B, Zagzag D, Nagasawa H, et al: Hypoxiainducible factor-1-dependent repression of E-cadherin in von Hippel-Lindau tumor suppressor-null renal cell carcinoma mediated by TCF3, ZFHX1A, and ZFHX1B. Cancer Res 66: 2725-2731, 2006

10. Koshiji M, Kageyama Y, Pete EA, Horikawa I, Barrett JC and Huang LE: HIF-1alpha induces cell cycle arrest by functionally counteracting Myc. EMBO J 23: 1949-1956, 2004.

11. An WG, Kanekal M, Simon MC, Maltepe E, Blagosklonny MV and Neckers LM: Stabilization of wild-type p53 by hypoxiainducible factor 1alpha. Nature 392: 405-408, 1998.

12. Guo K, Searfoss G, Krolikowski D, et al: Hypoxia induces the expression of the pro-apoptotic gene BNIP3. Cell Death Differ 8: 367-376, 2001.

13. Huang Y, Du KM, Xue ZH, et al: Cobalt chloride and low oxygen tension trigger differentiation of acute myeloid leukemic cells: possible mediation of hypoxia-inducible factor-1alpha. Leukemia 17: 2065-2073, 2003.

14. Jung JY and Kim WJ: Involvement of mitochondrial- and Fas-mediated dual mechanism in $\mathrm{CoCl}_{2}$-induced apoptosis of rat PC12 cells. Neurosci Lett 371: 85-90, 2004.

15. Ji Z, Yang G, Shahzidi S, et al: Induction of hypoxia-inducible factor-1alpha overexpression by cobalt chloride enhances cellular resistance to photodynamic therapy. Cancer Lett 244: 182-189, 2006.

16. Lee SG, Lee H and Rho HM: Transcriptional repression of the human p53 gene by cobalt chloride mimicking hypoxia. FEBS Lett 507: 259-263, 2001

17. Vengellur A, Woods BG, Ryan HE, Johnson RS and LaPres JJ: Gene expression profiling of the hypoxia signaling pathway in hypoxia-inducible factor 1alpha null mouse embryonic fibroblasts. Gene Expr 11: 181-197, 2003.

18. Yang SJ, Pyen J, Lee I, Lee H, Kim Y and Kim T: Cobalt chloride-induced apoptosis and extracellular signal-regulated protein kinase 1/2 activation in rat C6 glioma cells. J Biochem Mol Biol 37: 480-486, 2004

19. Araya J, Maruyama M, Inoue A, et al: Inhibition of proteasome activity is involved in cobalt-induced apoptosis of human alveolar macrophages. Am J Physiol Lung Cell Mol Physiol 283: L849-858, 2002.

20. Zou W, Yan M, Xu W, et al: Cobalt chloride induces PC12 cells apoptosis through reactive oxygen species and accompanied by AP-1 activation. J Neurosci Res 64: 646-653, 2001.

21. Kim HJ, Yang SJ, Kim YS and Kim TU: Cobalt chloride-induced apoptosis and extracellular signal-regulated protein kinase activation in human cervical cancer HeLa cells. J Biochem Mol Biol 36: 468-474, 2003.

22. Piret JP, Mottet D, Raes $\mathrm{M}$ and Michiels $\mathrm{C}$ : $\mathrm{CoCl}_{2}$, a chemical inducer of hypoxia-inducible factor-1, and hypoxia reduce apoptotic cell death in hepatoma cell line HepG2. Ann NY Acad Sci 973: 443-447, 2002.

23. Liu XH, Kirschenbaum A, Yao S, et al: Up-regulation of vascular endothelial growth factor by cobalt chloride-simulated hypoxia is mediated by persistent induction of cyclooxygenase- 2 in a metastatic human prostate cancer cell line. Clin Exp Metastasis 17: 687-694, 1999.

24. Van Lieshout T, Stanisz J, Espiritu V, Richardson M and Singh G: A hypoxic response induced in MatLyLu cells by cobalt chloride results in an enhanced angiogenic response by the chick chorioallantoic membrane. Int J Oncol 23: 745-750, 2003.

25. Lu N, Zhou H, Lin YH, Chen ZQ, Pan Y and Li XJ: Oxidative stress mediates $\mathrm{CoCl}(2)$-induced prostate tumour cell adhesion: role of protein kinase $\mathrm{C}$ and p38 mitogen-activated protein kinase. Basic Clin Pharmacol Toxicol 101: 41-46, 2007.

26. Ryu MH, Park JH, Park JE, Chung J, Lee CH and Park HR: Cobalt chloride stimulates phosphoinositide 3-kinase/Akt signaling through the epidermal growth factor receptor in oral squamous cell carcinoma. Biocell 34: 15-21, 2010.

27. Kyle RA and Rajkumar SV: Multiple myeloma. Blood 111: 2962-2972, 2008.

28. Parmar K, Mauch P, Vergilio JA, Sackstein R and Down JD: Distribution of hematopoietic stem cells in the bone marrow according to regional hypoxia. Proc Natl Acad Sci USA 104: 5431-5436, 2007.

29. Asosingh K, De Raeve H, de Ridder M, et al: Role of the hypoxic bone marrow microenvironment in 5T2MM murine myeloma tumor progression. Haematologica 90: 810-817, 2005. 
30. Hu J, Handisides DR, Van Valckenborgh E, et al: Targeting the multiple myeloma hypoxic niche with TH-302, a hypoxiaactivated prodrug. Blood 116: 1524-1527, 2010.

31. Kim SY, Bae S, Choi KH and An S: Hydrogen peroxide controls Akt activity via ubiquitination/degradation. Oncol Rep 26 : 1561-1566, 2011.

32. Chi JT, Wang Z, Nuyten DS, et al: Gene expression programs in response to hypoxia: cell type specificity and prognostic significance in human cancers. PLoS Med 3: e47, 2006.
33. Wang T, Xia D, Li N, et al: Bone marrow stromal cell-derived growth inhibitor inhibits growth and migration of breast cancer cells via induction of cell cycle arrest and apoptosis. J Biol Chem 280: 4374-4382, 2005

34. Huynh H, Ng CY, Ong CK, Lim KB and Chan TW: Cloning and characterization of a novel pregnancy-induced growth inhibitor in mammary gland. Endocrinology 142: 3607-3615, 2001.

35. Marhaba R and Zoller M: CD44 in cancer progression: adhesion, migration and growth regulation. J Mol Histol 35: 211-231, 2004. 